\title{
Hungaro Durum Rye-Breeding, Genome Composition and Amino Acid Content of the First Triticale Cultivar for Human Consumption
}

\author{
József Kruppa Jr. ${ }^{1}$, Klaudia Kruppa ${ }^{2}$ and József Kruppa ${ }^{1}$ \\ 1. Kruppa-Mag Research, Seed Producer and Distributor Ltd., Kisvárda, 4600, Hungary \\ 2. Department of Plant Genetic Resources, Agricultural Institute, Centre for Agricultural Research, Hungarian Academy of Sciences, \\ Martonvásár, 2462, Hungary
}

\begin{abstract}
Hungaro triticale cultivar was bred for human consumption and animal fodder in Kisvárda, Hungary. The breeding method applied for the recombinant secondary hexaploid triticale proved to be effective since the favourable traits of wheat, durum wheat and rye were successfully combined in the genome of the new cultivar. The first aim was to characterize the genome composition. Multicolour genomic in situ hybridization (mcGISH) was used for the genome compositional analysis. According to the results, the cultivar contains the wheat $\mathrm{AB}$ genome ( $\mathrm{AABB}=28$ chromosomes) and the whole rye $(\mathrm{R})$ genome $(\mathrm{RR}=14$ chromosomes). The presence of $\mathrm{D}$ genome, however, could not be detected within the detection limit of the GISH method. Hungaro is the very first triticale in Hungary that has been used for human consumption (milling industry, baking industry, pasta production). In this study, amino acid content of flours was measured. Amino acid investigations on Hungaro durum rye's flour showed that the quantity of essential amino acids, especially of methionine and cysteine, are higher in Hungaro durum rye than in the also investigated Ryefood rye cultivar and the GK Öthalom wheat cultivar. The genes inherited from the wheat species ensure high yield and great baking and dough making qualities. Therefore, its flour is suitable in itself for pastry and dough production (without mixing it with other flours). Its characteristics inherited from rye guarantee excellent abiotic and biotic resistance.
\end{abstract}

Key words: Triticale for human consumption, Hungaro durum rye, quality, GISH.

\section{Introduction}

In Hungary, triticale is generally produced on low fertility soils and is mainly used for animal foraging. When farmers intended to grow triticale for human consumption, they had to realise many unfavourable aspects: low or lacking gluten content, poor flour quality, unfavourable baking qualities and unfamiliarity to the milling and baking industry. In Europe and the Commonwealth of Independent States, triticale for human consumption is bred in several places and human use of its flour has been a significant goal, however, with little success so far. Up until now, the flour of the triticale cultivars has not

Corresponding author: József Kruppa Jr., Ph.D. student, research field: triticale quality. been suitable in itself for food (pastries, dough etc.) production. Hungaro is the very first cultivar in Hungary that has been used for human purposes.

In Hungary, even 10 years earlier, most of the triticale cultivars came from Poland. Nowadays, predominantly, the Hungarian varieties can be found on the arable lands. Successful ongoing triticale breeding programmes are on their ways in Martonvásár, Mosonmagyaróvár, Kisvárda and Szeged, too.

Kiss [1] summarised the aims of triticale breeding as follows: "In our days, it is already quite simple. Undoubtedly, producing clones and varieties with high productivity, winter hardiness, frost resistance, good forage quality and later, good flour quality" are needed. The most important genome combination is 
represented by Triticale turgidocereale (6x) since it combines the whole RR genome of rye with the whole AABB genome of tetraploide wheat. Hereinafter, the attention should be drawn to hexaploid triticale [2]. In the experiments of Tohver et al. [3], the baking trials showed that several triticale cultivars can be used for bread making by mixing wheat flour with a maximum of $70 \%$ of triticale flour. Varughese [4] wrote that the main deficiency of triticale known so far stems from its " $\mathrm{R}$ " genome: it deteriorates the baking qualities. In some research institutes, ongoing experiments aim to find out how it could be possible to transfer the allele harbouring glutenin with large molecular weight from " $D$ " genome to " $R$ " genome. If they succeed, the baking qualities of triticale will certainly reach the baking qualities of wheat. Hungaro triticale cultivar gained state recognition in 2005 [5], which makes it possible to produce a brand new food product: the high quality triticale bread. The secondary hexaploid triticales can contain genes originating from the D genome of the hexaploid (bread) wheat. Using this trait, a new, recombinant triticale cultivar for human consumption, named Hungaro, was created. Győri et al. [6] wrote that Hungaro triticale cultivar provides competitive raw material for bread making thanks to its greater resistance to the environmental impacts and its greater and healthier compositional properties. These traits offer new opportunities to produce healthy and residue-free food products in an environmentally friendly way. According to Bedő and Láng [7], triticale cannot replace rye or wheat; it is not better, nor worse than them. However, it does have a significant trait: it differs from the other cereals and has its own role and place in the cultivation. Besides the use of Polish varieties, wider spread of the Hungarian varieties can be expected $[8,9]$.

Based on the measurements performed at the Agricultural Instrumentation Centre of the University of Debrecen between 2002 and 2011, Hungaro durum rye had similar or higher protein content than wheat. Regarding its mineral content, $\mathrm{P}, \mathrm{K}, \mathrm{Ca}, \mathrm{Cu}, \mathrm{Mg}$ and
$\mathrm{Zn}$ contents are typically higher in Hungaro durum rye than in wheat [10-12]. This can facilitate higher mineral and microelements intake with nutrition. Its flour contains twice as much $\mathrm{E}, \mathrm{B}_{1}, \mathrm{~B}_{2}$ and $\mathrm{B}_{6}$ vitamins than wheat flour. It also enhances its importance in nutrition that the cultivar contains twice as much fibre than wheat flour, yet it contains $10 \%$ less carbohydrate and energy. Moreover, it has a delicious and unique taste. "The spread of triticale in human nutrition may offer new and healthy food alternatives besides the usual food products made of traditional cereals" [10].

The aim of this study was to determine the amino acid content of the newly developed Hungaro triticale and to identify its genome composition.

\section{Materials and Methods}

\subsection{Plant Material and Breeding Method}

The breeding method applied for Hungaro durum rye (Fig. 1) — crossing of secondary triticale cultivars $(2 \mathrm{n}=6 \mathrm{x}=42 \times 2 \mathrm{n}=6 \times=42)$-allows the recombination of characteristics. As a result, a large number of different hybrids are developed. Using this method, Hungaro durum rye, the first triticale cultivar for human consumption, was created by the development of recombinant hexaploid triticale genotypes $(2 n=6 \times=42 \times 2 n=6 \times=42)$ and along with continuous monitoring of their quality traits. Better baking quality of common wheat (Triticum aestivum) compared with the baking qualities of forage triticale varieties (X Triticosecale Wittmack) is a result of the DD genome pair in bread wheat. In hexaploid triticale, rye's RR genome pair substitutes the DD genome pair (AABBRR). For developing secondary triticale, octoploid triticale is crossed with the hexaploid one as it is shown in Fig. 1. For developing the breeding material of Hungaro cultivar, LAD 388 secondary hexaploid triticale clone was crossed with Presto secondary hexaploid triticale cultivar (LAD $388 \times$ Presto). After the crossing, Pedigree 


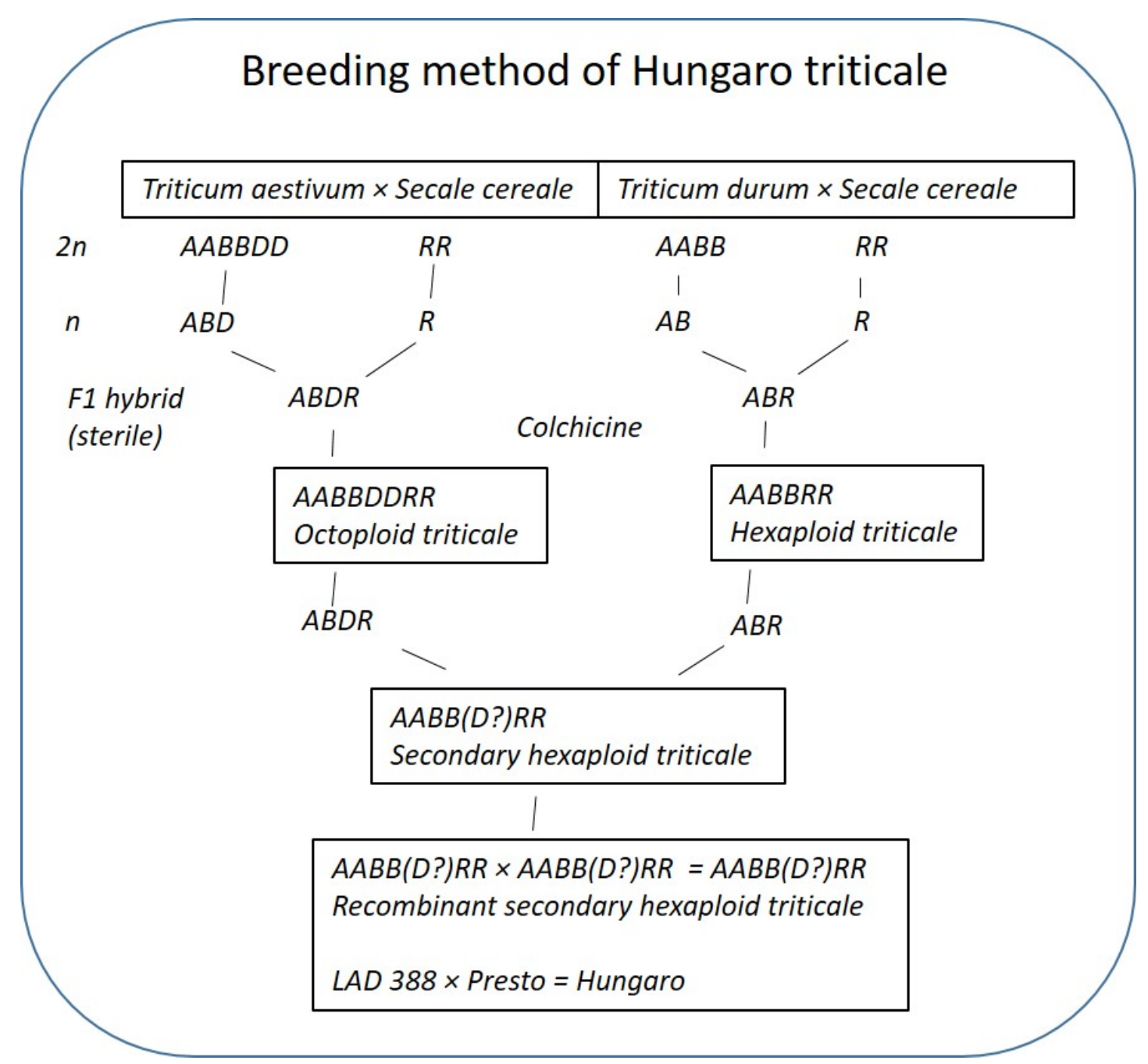

Fig. 1 Breeding method of combinant secondary hexaploid triticale.

method was applied to breed the recombinant triticale cultivar from the 2 nd population $\left(\mathrm{F}_{2}\right)$.

\subsection{Methods of Molecular Cytogenetic Investigations}

For the simoultaneous detection of rye $(\mathrm{R})$ and $\mathrm{D}$ genome chromosomes, multicolour genomic in situ hybridization (mcGISH) technique was used in Martonvásár [13]. The chromosome preparations made from the root tips were denatured. Besides the unlabelled durum wheat (AABB) genomic DNA, the hybridisation buffer contained biotin-11-dUTP-labelled rye (R) and digoxigenin-11-dUTP-labelled Aegilops tauschii (D) DNA. The hybridisation was done at $42{ }^{\circ} \mathrm{C}$, by placing the hybridisation buffer onto the pre-denatured chromosome spreads. The sequences labelled by biotin and digoxigenin were detected by Anti-Dig-Rhodamine and Streptavidin-FITC antibodies. The slides were screened using a Zeiss Axioskop-2 fluorescence microscope equipped with filter sets appropriate for DAPI (Zeiss Filterset 01) and for the simultaneous detection of FITC and Rhodamine (Zeiss filter set 24). Images were captured with a Spot CCD camera (Diagnostic Instruments) and processed with Image Pro Plus software (Media Cybernetics).

\subsection{Amino Acid Investigations}

For determining the amino acid content, good quality, freshly produced flours made from newly 

of the First Triticale Cultivar for Human Consumption

grown crops were used. The investigations were carried out at the Institute of Food Science, Quality Assurance and Microbiology of the University of Debrecen. Amino acid contents of the flours were determined according to the No.10 Appendix of the Decree No. 44 of 2003 (IV. 26.) FVM of the Ministry of Agriculture and Rural Development of the Hungarian Feedstuffs Codex (Codex Pabularis Hungaricus) using a BIOTRONIK LC 3000 instrument.

\section{Results and Discussion}

Hungaro durum rye, the first triticale cultivar for human consumption, was created by developing recombinant hexaploid triticale genotypes $(2 n=6 \times=$
$42 \times 2 \mathrm{n}=6 \times=42$ ) and along with continuous monitoring of their quality traits. For developing secondary triticale, octoploid triticale is crossed with the hexaploid one as it is shown in Fig. 1. For breeding Hungaro cultivar, LAD 388 secondary hexaploid triticale clone was crossed with Presto secondary hexaploid triticale cultivar (LAD $388 \times$ Presto). After the crossing, Pedigree method was applied to breed the recombinant triticale cultivar from the 2 nd population $\left(\mathrm{F}_{2}\right)$.

Using mcGISH, 14 rye chromosomes were detected among 42 chromosomes of the hexaploid Hungaro triticale cultivar (Fig. 2). Presence of the whole chromosome or segments belonging to the wheat D genome could not be detected by mcGISH.

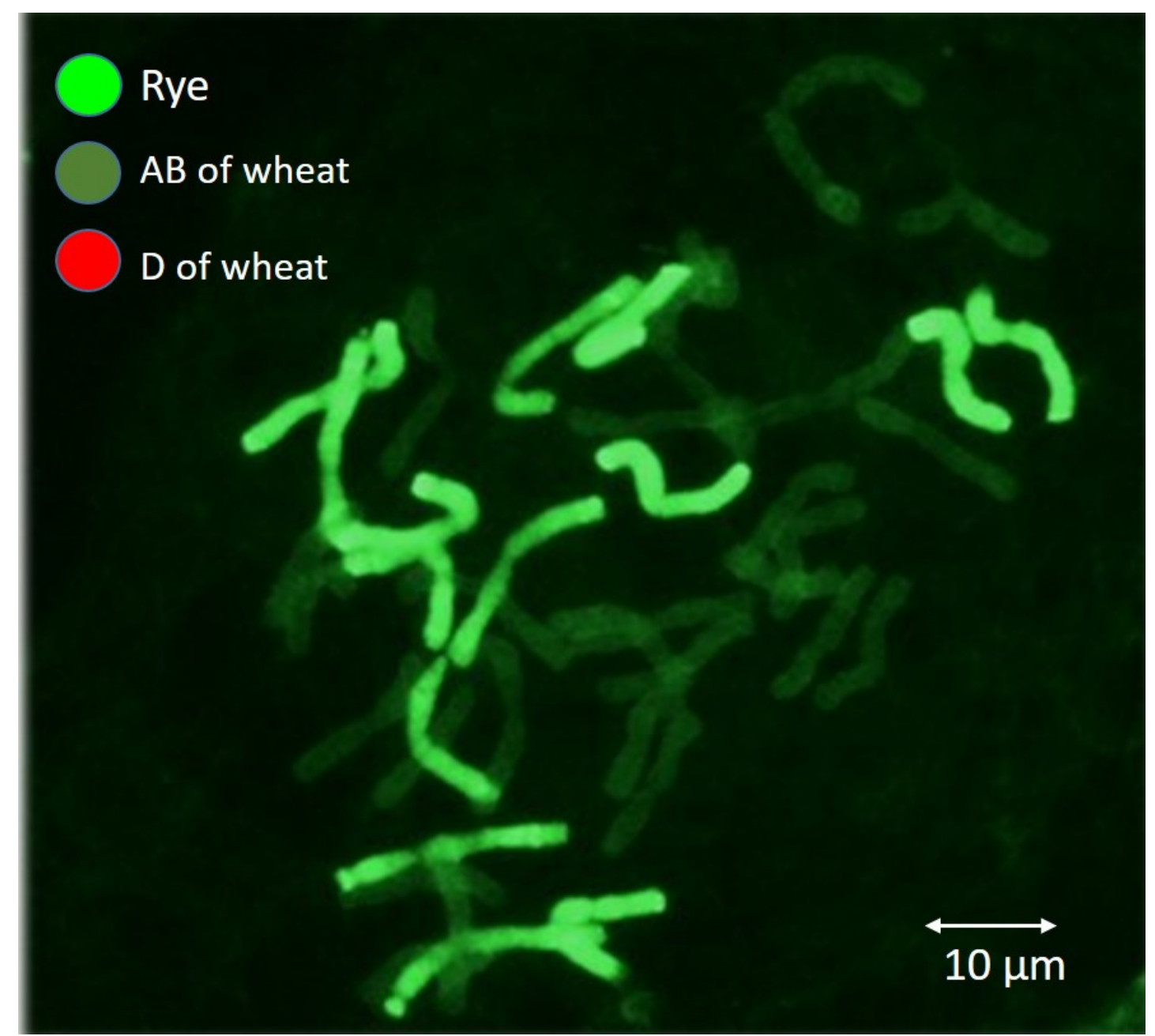

Fig. 2 Multicolour genomic in situ hybridisation (mcGISH) pattern of the chromosomes of triticale cultivar Hungaro.

Fourteen rye chromosomes (R genome) were detected light green; wheat chromosomes were unlabelled (dark green); D genome of wheat was not detected. 
McGISH is a very sensitive and accurate method of characterizing the genomes involved in allopolyploids and interspecific hybrid combinations. Mukai was the first who simultaneously discriminate the three genomes in hexaploid wheat [14]. Hexaploid bread wheat contains ABD genomes. The influence of the entire D-genome on milling and baking properties of bread wheat varieties has been reported from the 1960s [15]. The water insoluble gluten proteins are responsible for the elasticity and cohesiveness (strength) of dough and are important determinants of breadmaking quality. Of the glutenins, subunits $5+10$ encoded by the $\mathrm{D}$ genome have been found to have the largest positive effect on dough strength [16]. There has been considerable interest in improving the dough strength and quality of triticale (X Triticosecale Whittm.) to use them in bread-like products. It has been pointed out that in secondary hexaploid triticale lines some rye chromosomes could have been substituted by wheat chromosomes from the D-genome [17] (Fig. 1). Lukaszewski and Curtis [18] transferred of the Glu-D1 gene from chromosome 1D to chromosome $1 \mathrm{R}$ in hexaploid triticale using induced homoeologous pairing. Later Lukaszewski published hexaploid triticale lines with cytogenetically engineered $1 R$, thereby creating the genetic potential for breeding bread-making triticales [18].

Amino acid investigations on Hungaro durum rye's flour showed that the quantity of essential amino acids, especially of methionine and cysteine, are higher in Hungaro durum rye than in the also investigated Ryefood rye cultivar and the GK Öthalom wheat cultivar (Table 1). It had also good parameters in case of glycine and valine. Most of the amino acids in triticale had similar parameters than that those of wheat (e.g., Aspartic acid, threonine, alanine, isoleucine, leucine, tyrosine, lysine).

Hungaro durum rye is the first Hungarian-bred triticale for human consumption that combines the characteristics (genomes) of durum wheat and rye, but it also harbours the characteristics of common bread wheat. Hungaro triticale candidate cultivar for human consumption and foraging was applied and so it has gained state recognition and plant variety protection.

Table 1 Aminoacid content (m/m\% = g/100 g) of triticale cultivar Hungaro, rye cv Ryefood and of wheat cv GK Öthalom.

\begin{tabular}{llll}
\hline Amino acid* & $\begin{array}{l}\text { Hungaro triticale } \\
\mathrm{m} / \mathrm{m} \%\end{array}$ & $\begin{array}{l}\text { Ryefood rye } \\
\mathrm{m} / \mathrm{m} \%\end{array}$ & $\begin{array}{l}\text { GK Öthalom wheat } \\
\mathrm{m} / \mathrm{m} \%\end{array}$ \\
\hline ASP & 0.56 & 0.78 & 0.59 \\
THR & 0.35 & 0.34 & 0.32 \\
SER & 0.46 & 0.44 & 0.55 \\
GLU & 2.65 & 3.77 & 3.94 \\
GLY & 0.59 & 0.46 & 0.46 \\
ALA & 0.35 & 0.21 & 0.38 \\
CYS & 0.27 & 0.13 & 0.22 \\
VAL & 0.55 & 0.49 & 0.44 \\
MET & 0.21 & 0.15 & 0.19 \\
ILE & 0.35 & 0.37 & 0.34 \\
LEU & 0.76 & 0.66 & 0.81 \\
TYR & 0.26 & 0.23 & 0.24 \\
PHE & 0.52 & 0.47 & 0.49 \\
HIS & 0.29 & 0.28 & 0.34 \\
LYS & 0.36 & 0.48 & 0.36 \\
ARG & 0.25 & 0.40 & 0.38 \\
PRO & 1.05 & 1.82 & 1.35 \\
\hline
\end{tabular}

*Abbreviated and whole names of the amino acids: ASP - aspartic acid, THR - threonine, SER-serine, GLU-glutamic acid, GLY — glycine, ALA — alanine, CYS — cysteine, VAL—valine, MET — methionine, ILE—isoleucine, LEU—leucine, TYR—tyrosine, PHE - phenylalanine, HIS — histidine, LYS — lysine, ARG — arginine, PRO — proline. 
Human use of the cultivar (in the milling, baking and confectionery industry and for dough production) has been launched under the name of 'Hungaro durum rye', which has been recognised by the National Food Chain Safety Office in an official statement. The genes inherited from the wheat species ensure high yield and great baking and dough making qualities. Therefore, its flour is suitable in itself for pastry and dough production (without mixing it with other flours). Its characteristics inherited from rye guarantee excellent abiotic and biotic resistance.

\section{Conclusions}

Triticale, a man made hybrid of wheat and rye was created to combine the high yielding capacity of wheat with the excellent stress tolerance of rye. Only secondary hexaploid triticales have truly demonstrated triticale's promise. The use of hexaploid triticale as a crop for human consumption has been limited by its inferior bread-making quality. As Hungaro triticale has good parameters in bread-making qualities, the authors expected the presence of a D-genome segment in its genome but mcGISH experiments did not prove it. While examining chromosomes in mitosis/metaphase, it may happen that the size of the translocated segment falls beyond the detection limit of mcGISH. Therefore, application of molecular markers in the future is planned.

In the present days, when the world has to face the damages resulting from environmental pollution, Hungaro triticale (Hungaro durum rye) provides new opportunities to enhance environmentally friendly cereal production and to produce healthy food products from these cereals.

\section{References}

[1] Kiss, Á. 1968. Triticale, a New Cereal of Sand Soil. Mezőgazdasági Kiadó, Budapest. (in Hungarian)

[2] Schlegel, R. 1996. "Triticale-Today and Tomorrow." In Triticale: Today and Tomorrow, edited by Guedes-Pinto, H., Darvey, N., Carnide, V. P. Kluwer Academic Publishers, the Netherlands, 21-31.
[3] Tohver, M., Kann, A., Taht, R., Mihhalevski, A., and Hakman, J. 2005. "Quality of Triticale Cultivars Suitable for Growing and Bread-Making in Northern Conditions." Food Chemistry 89: 125-32.

[4] Varughese, G. 1996. "Triticale: Present Status and Challenges Ahead." In Triticale: Today and Tomorrow, edited by Guedes-Pinto, H., Darvey, N., and Carnide, V. P. Kluwer Academic Publishers, the Netherlands, 16-9.

[5] Kruppa, J., and Hoffmann, B. 2006. "New Triticale (Triticum turgidocereale) and Rye (Secale cereal) Varieties for Human Consumption and Animal Fodder." Seed Research Development and Environment 20: 43-5. (in Hungarian)

[6] Győri, Z., Kruppa, J., Ungai, D., Mile, I. G., and Sipos, P. 2009. "Examination of Technological and Nutritional Properties of Breads Made from Triticale Flour." In Proceedings of the 5th International Congress Flour-Bread: the 7th Croatian Congress of Cereal Technologists, Opatija, Croatia, October 21-23, 2009, 503-7.

[7] Bedő, Z., and Láng, L. 1992. "Naturalization of Polish Triticale Varieties in Hungary." Rye and Triticale Growing 22-4. (in Hungarian)

[8] Bóna, L. 2004. "Triticale in Hungary." In Triticale Improvement and Production, Triticale FAO Book. S., edited by Mergoum, M., Rome, 119-21.

[9] Bóna, L. 2011. "Triticale, the Young Plant Species with New Opportunities.” In MAG Arany Évkönyv, edited by Oláh,, I. Bétaprint Press, Budapest, 39-43. (in Hungarian)

[10] Kruppa, J., and Ifj. Kruppa, J. 2011. "New Results in Triticale Breeding and Utilization.” In Mag Arany Évkönyv, 106-9. (in Hungarian)

[11] Ifj Kruppa, J., Kruppa, K., and Kruppa, J. 2014. "Hungaro Durum Rye-Our New Dietary Cereal." In Conference of Young Biotechnologists in Hungary, Programme and Abstract Book, edited by Maráz, A., Pfeiffer, I., and Vágvölgyi, Cs. JATE Press, 68.

[12] ifj Kruppa, J., Kruppa, K., and Kruppa, J. 2016. "Hungaro Durumrye-The First Food Triticale Variety." In Book of Abstracts 9th International Triticale Symposium, edited Bona, L., and Cooper, K. V. Cereal Research Nonprofit Ltd., 24.

[13] Molnár, I., Benavente, E., and Molnár-Láng, M. 2009. "Detection of Intergenomic Chromosome Rearrangements in Irradiated Triticum aestivum-Aegilops biuncialis Amphiploids by Multicolour Genomic in Situ Hybridization.” Genome 52: 156-65.

[14] Mukai, Y., Nakahara, Y., and Yamamoto, M. 1993. "Simultaneous Discrimination of the Three Genomes in Hexaploid Wheat by Multicolor Fluorescence in Situ 

of the First Triticale Cultivar for Human Consumption

Hybridization Using Total Genomic and Highly Repeated DNA Probes." Genome 36: 489-94.

[15] Kaltsikes, P. J., Evans, L. E., and Bushuk, W. 1968. "Durum-Type Wheat with High Bread-Making Quality." Science 59: 211-3.

[16] Smith, R. L., Schweder, M. E., and Barnett, R. D. 1994. "Identification of Glutenin Alleles in Wheat and Triticale Using PCR-Generated DNA Markers." Crop Science 34:
1373-8.

doi:10.2135/cropsci1994.0011183X003400050042x.

[17] Merker, A. 1975. "Chromosome Composition of Hexaploid Triticale." Hereditas 80: 41-52.

[18] Lukaszewski, A. J., and Curtis, C. A. 1992. "Transfer of the Glu-D1 Gene from Chromosome 1D of Bread Wheat to Chromosome 1R in Hexaploid Triticale." Plant Breeding 109: 203-10. 